\title{
Science journals permit open-access publishing for Gates Foundation scholars
}

The provisional agreement may set a precedent for other funders and journal publishers.

Richard Van Noorden

14 February 2017

If research funders demand open-access publishing, will subscription journals acquiesce? An announcement today by the publisher of Science suggests they will — as long as that funder is as influential as the Bill \& Melinda Gates Foundation.

The global health charity, based in Seattle, Washington, has partnered with the American Association for the Advancement of Science (AAAS) in a year-long agreement to "expand access to high-quality scientific publishing". This means that Gates-funded research can be published on open-access (OA) terms in Science and four other AAAS journals.

"This is the first time the AAAS is offering open-access publishing for Science and the subscription-based sister journals," says Meagan Phelan, a spokesperson for the AAAS in Washington DC.

However, the AAAS-Gates agreement is provisional, says Dick Wilder, associate general counsel with the Gates Foundation's Global Health Program, and will be reviewed later this year to see if it continues for 2018. "We hope and they hope that this is something that will continue indefinitely," he adds.

Scholars were previously not allowed to publish Gates-funded research in some AAAS journals because they didn't accommodate Gates' strict OA policy. The same OA clash exists at other influential subscription journals, including Nature. (Nature's news team is editorially independent of the journal Nature). Gates' policy stipulates that researchers must make their resulting papers and data open immediately upon publication, and under a licence that allows unrestricted reuse for commercial purposes.

Open-access advocates applauded the move. "Good for Science for agreeing to accommodate the Gates policy, and good for Gates in refusing to accommodate the previous terms and conditions of Science," says Peter Suber, director of the Harvard Open Access Project and the Harvard Office for Scholarly Communication in Cambridge, Massachusetts.

\section{A temporary arrangement}

The Gates Foundation usually pays journals' publishing fees for individual studies in order to assure OA content. But as part of this new agreement, the Foundation will pay AAAS a lump sum of US $\$ 100,000$ for the year, says Wilder.

The Foundation estimates that it will publish between 10 and 15 studies in AAAS journals this year, and says that it will work with AAAS to develop a report looking at the sustainability of OA publishing in journals such as Science, which make money largely from library subscriptions.

Suber says that the agreement may reassure other funders that they can try to adopt strong OA policies without locking their grantees out of major journals. "The Gates Foundation is showing that other foundations should not worry about journal embargo and licensing terms in the first place, or if they do worry, they should act even without waiting for the worry to lift," he says.

\section{Future partners?}

The Wellcome Trust in London, UK, is one funder that has pushed for open-access policies. But if the publisher does not offer OA, the organization allows a six-month embargo period before papers must be made open to the public.

“We welcome AAAS's efforts to ensure Gates grantees' publications are openly available, and look forward to exploring similar opportunities for Wellcome-funded research," says Robert Kiley, who leads the charity's open-access efforts.

The AAAS-Gates partnership is the only such arrangement AAAS is considering for now, says Phelan. But "AAAS will consider additional partnerships at the end of 2017". 
Science is not the only journal looking to accommodate Gates' policy in some way, Wilder says. The foundation is in ongoing discussions with the other journals, and more announcements may come soon, he adds.

Spokespeople for the Proceedings of the National Academy of Sciences and the New England Journal of Medicine say their respective journals are still discussing the matter. Nature's news team is waiting on comment from other publishers that do not currently comply with Gates' OA policy.

Nature | doi:10.1038/nature.2017.21486 